\title{
The Research on the Spatial Effect of the Urbanization of China to Expand Domestic Demand
}

\author{
Chaojun $\mathrm{Ni}$ \\ Xinjiang shihezi shibei four-way 31 district no. 1, 221, 141,china \\ ncj1999@163.com
}

Keywords: Urbanization; Demand; Influence; Panel data model

Abstract. Based on the panel data of China's 31 provincial from 2005-2012, the paper using the spatial panel model to study the China's urbanization impact on domestic demand.

\section{The Origin of the Problem}

The number of population which live in town for long time increased from 70 million to 730 million from 1978 to 2013, and the urban population increased from $17.9 \%$ to $53.7 \%$, with an average annual increase of 1.02 percentage points. The number of cities increased from 193 to 658 , and the number of town which establish by government approve increase from 2173 to 20113. At present, the rate of China's resident population urbanization is $53.7 \%$, the rate of household population urbanization is only about $36 \%$, not only much lower than the average level of $80 \%$ in developed countries, but also below the developing countries for $60 \%$ which have the similar average income with our country, it still have a large space for development. With the rapid development of China's economy, China's urban and rural incomes also increased rapidly, but they have different growth tendency between urban and rural. China's per capita disposable income of urban households from 343.4 yuan in 1978, increased to 24564.7 yuan in 2012, an average annual increase of $13.38 \%$, China's per capita net income of rural households from 133.6 yuan in 1978, increased to 7916.6 yuan in 2012, an average annual increase of $12.76 \%$. China's urban and rural residents Engel coefficient from $57.5 \%$ and $67.7 \%$ in 1978 , down to $36.2 \%$ and $39.3 \%$ in 2012. So, whatever from the absolute number of income or growth rate, or from the Engel coefficient of view, China's urban consumption is better than rural areas, while the gap between urban and rural consumption is enlarging. In a sense, China open the domestic consumer market, expanding domestic demand for driving the domestic rural market or farmers' consumption by the urbanization strategy. The national new urbanization strategy is an opportunity for this paper, with China's reform and opening up as well as the process of market's depth, the economic links between regions are becoming closer day by day, the economic factors have radiation effect on each other in space, therefore, using the spatial econometric model to research the impact of urbanization on the expansion of domestic demand.

\section{Index Selection and Model Setting}

Indicator Selection and Data Description. This paper involves two variables: urbanization and domestic demand. In the selection of indicators, urbanization rate (URB). As domestic demand mainly includes investment demand and consumption demand, the domestic demand in this paper refers to domestic consumption demand, this paper chooses the consumption rate (CS). In order to explore the regional differences and effects of expanding domestic demand in urbanization fully, this paper leads into four control variables, which include the proportion of the industrial structure (CJ, the ratio of the output value of the secondary and tertiary industries to the total output value), the level of economic development (the logarithm of the data, LNGDP, GDP per capita, the ratio of the primary industry output value to total output value), social security level (LSS, the ratio of social security expenditure to GDP) and per capita net income of farmers (this paper takes the logarithm of this data, LNSR, per capita net income of farmers).

The data in this paper comes from the "China Statistical Yearbook" from 2006 to 2013,this paper 
selects the statistical data of 31 provinces, municipalities and autonomous regions from 2005 to 2012, and completes it by software Matlab and Geoda. descriptive statistical results in Table 1.

Table 1 Descriptive statistical results

\begin{tabular}{ccccccc}
\hline & Mean & Median & Maximu & Minimu & Std. Dev. & Observations \\
\hline URB & 0.500667 & 0.47 & 0.89 & 0.27 & 0.14352 & 240 \\
LNG & 10.0985 & 10.085 & 11.44 & 8.59 & 0.58976 & 240 \\
$\overline{\text { CS }}$ & 0.3505 & 0.34 & 0.62 & 0.22 & 0.064235 & 240 \\
CJ & 0.883223 & 0.8799 & 0.9937 & 0.6651 & 0.059613 & 240 \\
LNS & 8.526173 & 8.49335 & 9.7872 & 7.5374 & 0.471254 & 240 \\
LSS & 0.061511 & 0.05865 & 0.1867 & 0.0244 & 0.023608 & 240 \\
\hline
\end{tabular}

Model Settings. Spatial Dubin model is a general form of spatial lag model and spatial error model. For the sake of generality, the model is set as the spatial panel Dubin model:

$$
\begin{aligned}
& C S_{i t}=c+\rho \sum_{j=1}^{30} W_{i j} C S_{j t}+a_{1} U R B_{i t}+b_{1} L_{n} G D P_{i t}+c_{1} C J_{i t}+d_{1} L_{n S R_{i t}}+e_{1} L S S_{i t} \\
& +a_{2} \sum_{j=1}^{30} W_{i j} U R B_{j t}+b_{2} \sum_{j=1}^{30} W_{i j} L n G D P_{j t}+c_{2} \sum_{j=1}^{30} W_{i j} C J_{i t}+d_{2} \sum_{j=1}^{30} W_{i j} L n S R_{j t}+e_{2} \sum_{j=1}^{30} W_{i j} L S S_{j t} \\
& +\mu_{i}+\lambda_{i}+\varepsilon_{i}
\end{aligned}
$$

\section{Empirical Analysis}

Model test and Choice. As can be seen from table 2, the different fixed effects regression model of LM and LM test, mostly through the test of significance, and the spatial lag model of LM and LM test statistics are greater than the spatial error model, spatial error model should be more reasonable. Further, we can use Wald and LR to test whether the spatial model can be simplified as a spatial lag model and spatial error model (see Table 3). The test results showed that Wald _ spatial _ lag and LR_ spatial _ lag statistics were 5.382 and 6.6783, with the probability values of prob _ spatial _ lag were 0.3711 and 0.2457 , the original assumptions are accepted at the $1 \%$ level; Wald _ spatial _error and LR _ spatial _ error statistics were 5.8622 and 6.9946, with the probability values of prob _ spatial _ lag were 0.3199 and 0.221 ,also under the significance level of $1 \%$ to accept the null hypothesis. It can be concluded that the spatial error model is more consistent with the objective description of this paper. In order to compare the robustness of the model estimation, the article also gives the spatial lag panel estimation results of the model. 
Table 2 Non spatial panel model estimation and spatial auto-correlation test

\begin{tabular}{|c|c|c|c|c|}
\hline variable & nonFE & sFE & $\mathrm{tFE}$ & stFE \\
\hline \multirow{2}{*}{$\mathrm{C}$} & $0.889919 * * *$ & & & \\
\hline & 10.890245 & & & \\
\hline \multirow{2}{*}{ URB } & $0.096759 * * *$ & 0.229347 & 0.473367 & $0.204447 * *$ \\
\hline & 2.677964 & 2.336386 & 8.671385 & 2.064825 \\
\hline \multirow{2}{*}{ LNGDP } & -0.274877 & -0.272121 & -0.341691 & -0.267485 \\
\hline & -16.664639 & -12.188793 & -20.638056 & -11.385456 \\
\hline \multirow{2}{*}{$\mathrm{CJ}$} & $0.328241 * * *$ & -0.038181 & 0.387835 & -0.040634 \\
\hline & 4.847403 & -0.280759 & 6.519495 & -0.307859 \\
\hline \multirow{2}{*}{ LNSR } & $0.219496 * * *$ & 0.246965 & 0.133724 & 0.062854 \\
\hline & 12.08046 & 10.993283 & 7.090232 & 1.523291 \\
\hline \multirow{2}{*}{ LSS } & $0.432639 * * *$ & -0.02971 & -0.29732 & -0.153343 \\
\hline & 3.863122 & -0.185128 & -2.269736 & -0.933844 \\
\hline $\mathrm{R}^{2}$ & 0.6368 & 0.6825 & 0.7018 & 0.5406 \\
\hline$\sigma^{2}$ & 0.0015 & 0.0002 & 0.0012 & 0.0002 \\
\hline $\log L$ & 440.3414 & 661.1571 & 472.9148 & 677.0051 \\
\hline $\begin{array}{l}\text { LM test no spatial } \\
\text { lag }\end{array}$ & $12.0544 * * *$ & $6.672 * * *$ & $6.8159 * * *$ & 0.2955 \\
\hline $\begin{array}{l}\text { robust LM test no } \\
\text { spatial lag }\end{array}$ & 0.9987 & 2.0351 & 0.8644 & 0.6208 \\
\hline $\begin{array}{l}\text { LM test no spatial } \\
\text { error }\end{array}$ & $26.483 * * *$ & $4.8262 * *$ & $22.2701 * * *$ & 0 \\
\hline $\begin{array}{l}\text { robust LM test no } \\
\text { spatial error }\end{array}$ & $15.4273 * * *$ & 0.1894 & $16.3186^{* * *}$ & 0.3253 \\
\hline $\begin{array}{c}\text { The joint } \\
\text { significance test of } \\
\text { fixed space and } \\
\text { fixed time }\end{array}$ & LR Statistic & $\begin{array}{l}\text { Degrees of } \\
\text { freedom }\end{array}$ & prob & \\
\hline Space fixed effect & 408.1806 & 30 & 0 & \\
\hline Fixed time effect & 31.6961 & 8 & 0 & \\
\hline wald test(SAR) & 5.382 & & 0.3711 & \\
\hline LR test(SAR) & 6.6783 & & 0.2457 & \\
\hline wald test(SER) & 5.8622 & & 0.3199 & \\
\hline LR test(SER) & 6.9946 & & 0.221 & \\
\hline
\end{tabular}

According to different control space and time effects of two kinds of non observable effects, which are divided into four kinds namely no fixed effect (nonFE), time fixed effects (tFE), spatial fixed effect (sFE), space time fixed effect (stFE). In parentheses is the $\mathrm{t}$ statistic.*,**,***, *respectively, through the $10 \%, 5 \%, 1 \%$ level of significance test. The following table is the same.

\section{Result Analysis}

Table 3 shows the estimation results of different fixed effects under space Durbin panel model. The results show that, compared with the non spatial panel model (Table 2), the spatial Durbin model of $R^{\wedge} 2$ and natural $\log$ likelihood function values of the spatial LogL model are improved, model of discrete degree $\sigma^{\wedge} 2$ is relatively smaller. 
Spatial error model regression results show that the level of domestic demand in a certain province is affected not only by the level of domestic demand, but also by the level of domestic demand in neighboring provinces. The regression coefficient of $\mathrm{W}^{*} \mathrm{CS}(\mathrm{v})$ is 0.55097 , and through a significant test of $1 \%$ level. The level of urbanization has a positive effect on expanding domestic demand. The urbanization level of expanding domestic demand of regression coefficient is 0.513499 ,through the test of the significance of the level of $1 \%$,this suggests that every $1 \%$ increase of urbanization level, can drive the domestic demand $0.513499 \%$ improvement. There is a negative relationship between the level of economic development and the expansion of domestic demand. The two showed a negative correlation, the correlation coefficient was -0.3722 , indicating that under the premise of the other conditions unchanged,1 unit per capita GDP increase, the domestic demand will reduce 0.3722 units. For the level of the industrial structure has a significant positive influence to expand domestic demand. Regression results show that the level of industrial structure and expand the domestic demand of regression coefficient is 0.323764 , through a $1 \%$ significance level. Per capita net income of farmers for the promoting function of expanding domestic demand is weak. There is a positive correlation between the per capita net income of farmers and the domestic demand, the regression coefficient is 0.186952 , indicating that the per capita net income of farmers increased by 1 units, the domestic demand will rise by 0.186952 units..

The level of social security has a negative impact on the expansion of domestic demand. According to the regression results, the regression coefficient of social security level and domestic demand is -0.2851 , which has passed the $1 \%$ significance level test.

Table 3 results of spatial lag model and spatial error model

\begin{tabular}{|c|c|c|c|c|c|c|c|c|}
\hline \multirow[b]{2}{*}{ variable } & \multicolumn{4}{|c|}{ SLM } & \multicolumn{4}{|c|}{ SEM } \\
\hline & nonFE & $\mathrm{sFE}$ & $\mathrm{tFE}$ & stFE & nonFE & $\mathrm{sFE}$ & $\mathrm{tFE}$ & stFE \\
\hline $\mathrm{C}$ & $\begin{array}{c}0.7184 * * * \\
7.2072\end{array}$ & & & & & & & \\
\hline URB & $0.1095 * * *$ & 0.1758 & $\begin{array}{c}0.46624 * * \\
*\end{array}$ & $0.1948 *$ & -0.0264 & 0.1943 & $\begin{array}{c}0.513499 * \\
* *\end{array}$ & 0.2044 \\
\hline LNGDP & $\begin{array}{c}3.0868 \\
-0.2777 * * \\
*\end{array}$ & $\begin{array}{c}1.6950 \\
-0.2579 * * \\
*\end{array}$ & $\begin{array}{c}8.5330 \\
-0.3419 * * \\
*\end{array}$ & $\begin{array}{c}1.8277 \\
-0.2653 * * \\
*\end{array}$ & $\begin{array}{c}-1.0943 \\
-0.2898 * * \\
*\end{array}$ & $\begin{array}{c}1.8357 \\
-0.2613 * * \\
*\end{array}$ & $\begin{array}{c}10.7600 \\
-0.3722 * * \\
*\end{array}$ & $\begin{array}{c}1.9195 \\
-0.2675^{* *} \\
*\end{array}$ \\
\hline $\mathrm{CJ}$ & $\begin{array}{l}-17.1999 \\
0.292 * * *\end{array}$ & $\begin{array}{c}-10.8228 \\
-0.0305\end{array}$ & $\begin{array}{c}-20.5434 \\
0.358066^{*} \\
* *\end{array}$ & $\begin{array}{c}-10.4895 \\
-0.0376\end{array}$ & $\begin{array}{c}-17.2370 \\
0.358255^{*} \\
* *\end{array}$ & $\begin{array}{c}-10.8093 \\
-0.0443\end{array}$ & $\begin{array}{c}-24.3596 \\
0.323764 * \\
* *\end{array}$ & $\begin{array}{c}-10.5872 \\
-0.0406\end{array}$ \\
\hline LNSR & $\begin{array}{c}4.4769 \\
0.2357 * * *\end{array}$ & $\begin{array}{c}-0.2152 \\
0.241917 * \\
* *\end{array}$ & $\begin{array}{c}6.0703 \\
0.1511 * * *\end{array}$ & $\begin{array}{c}-0.2654 \\
0.075466 *\end{array}$ & $\begin{array}{c}5.6557 \\
0.344141 * \\
* *\end{array}$ & $\begin{array}{c}-0.3165 \\
0.237507 * \\
* *\end{array}$ & $\begin{array}{c}6.2391 \\
0.186952 * \\
* *\end{array}$ & $\begin{array}{c}-0.2863 \\
0.0629\end{array}$ \\
\hline LSS & $\begin{array}{c}13.4929 \\
0.4838 * * *\end{array}$ & $\begin{array}{l}10.3119 \\
0.0266\end{array}$ & $\begin{array}{c}8.0201 \\
-0.2228 *\end{array}$ & $\begin{array}{r}1.6620 \\
-0.1232\end{array}$ & $\begin{array}{c}20.3023 \\
0.551464 * \\
* *\end{array}$ & $\begin{array}{l}9.8068 \\
-0.0124\end{array}$ & $\begin{array}{c}10.7396 \\
-0.2851 * *\end{array}$ & $\begin{array}{r}1.4180 \\
-0.1533\end{array}$ \\
\hline$\rho$ & $\begin{array}{c}4.4064 \\
0.2319 * * *\end{array}$ & $\begin{array}{r}0.1581 \\
0.14899 *\end{array}$ & $\begin{array}{c}-1.6903 \\
0.172959 * \\
* *\end{array}$ & $\begin{array}{r}-0.6913 \\
0.0689\end{array}$ & 4.8900 & -0.0736 & -2.4969 & -0.8683 \\
\hline$v$ & & & & & $\begin{array}{c}0.710958 * \\
* *\end{array}$ & $0.18997 * *$ & $\begin{array}{c}0.55097 * * \\
*\end{array}$ & 0.0640 \\
\hline $\mathrm{R}^{2}$ & 0.6586 & 0.9440 & 0.7335 & & 0.2662 & 0.9422 & 0.9495 & 0.6953 \\
\hline$\sigma^{2}$ & 0.0014 & 0.0003 & 0.0011 & & 0.0015 & 0.0003 & 0.0002 & 0.0009 \\
\hline $\operatorname{LogL}$ & 446.1908 & 663.1038 & 476.3845 & & 421.0073 & 662.5438 & 677.0052 & 489.9701 \\
\hline
\end{tabular}




\section{Conclusion}

Based on the 2005-2012 China's 31 provincial panel data, in the inspection of urbanization in China to expand domestic demand, on the basis of whether there is a spatial correlation, using spatial econometric model and studying the urbanization impact on expanding domestic demand. The conclusions are obtained as follows.

First, there is obvious spatial dependence of domestic demand in china. The spatial correlation between the expansion of domestic demand in China is increasing, and the phenomenon of expanding domestic demand is obvious. Therefore, we should take full account of the spatial linkage effect between provinces. When the government plans to expand domestic demand, Should give full play to the expansion of domestic demand spatial spillover effect, Strengthen exchanges and cooperation between regions, promote the trans-regional flow of resource elements and agglomeration, and To achieve the maximum allocation of resource elements, the farthest radiation.

Second, the level of urbanization, the level of industrial structure and the per capita net income of farmers have a positive effect on the expansion of domestic demand, and the level of urbanization and the level of industrial structure play a more important role in expanding domestic demand. The per capita net income of farmers has a weak role in promoting domestic demand, which is worthy of attention.

\section{References}

[1] Xin-hua jian, huang kun. China's urbanization level and the speed of the empirical analysis and prospect forecast [J]. Journal of economic research,2010, 45(3): 28-39

[2] China Academy of reform and development. Urbanization of people [M]. Beijing: China Economic Publishing House, 2013: 20-26

[3] Masahisa. Fujita, Krugman P R ,Venables A. The spatial economy.MIT press, 1999.

[4] Venables A J,Equilibrium locations of vertically linked industries. International Economic Review.1996:341-359

[5] Duesenberry, J.S.The theory of income, savings and consumption behavior [M]. Hou Jiaju translation. Taiwan's economic research, 1957: 35-39 